DOI: $10.17117 /$ na.2016.09.02.365

http://ucom.ru/doc/na.2016.09.02.365.pdf

Поступила (Received): 02.09.2016

\title{
Эды Н.A.
}

\section{Формирование и развитие композиционных и} структурных особенностей мавзолеев на территории

Восточной Анатолии и Нахчывана с учетом их историко-географических взаимосвязей

\author{
Edi N.A. \\ Formation and development of compositional and structural \\ features of the mausoleums in Eastern Anatolia and Nakhchivan \\ with regard to their historical and geographical relationships
}

В статье рассматриваются все типы мавзолеев в Восточной Анатолии и Нахчыване эпохи правления Сельджуков и их атабеков. Выделены основные параметры архитектурного формообразования, конструкций и элементов, а также кладки, облицовки и декоративно-художественных приемов

Ключевые слова: Сельджуки, мавзолей, башенный тип, декоры, Восточная Анатолия, Нахчыван

Эды Наджи Абдулкадыр оглы

Аспирант, преподаватель

Университет им. И. Чечена

Турция, г. Агры
The article considers all types of mausoleums in Eastern Anatolia and Nakhchivan of the Seljuk government and their Atabeks. It obtained main settings of architectural form building, structures and elements, as well as masonry, cladding and decorative and artistic methods

Key words: Seljuks, mausoleum, tower type, decorations, Eastern Anatolia, Nakhchivan

Edi Naji Abdulkadir oglu

Graduate, teacher

University named I. Chechen

Turkey, Agri

Мемориальные памятники эпохи сельджуков в Восточной Анатолии отличаются богатством своего многообразия, в котором были выражены все условия для формирования архитектуры этой типологии сооружений. То же самое можно сказать и о мемориальной архитектуре того же периода на территории Азербайджана, которая оказала огромное влияние на развитие наиболее важной группы мавзолеев или тюрбе, которую составили памятники, называемые «башенными». Но если в регионах Азербайджана, преимущественно в южных Нахчыване, Мараге, Урмие и т.д. - большинство из них было построено из обожженного кирпича с применением каменных архитектурных деталей, то в Восточной Анатолии, например, в Ахлате или Эрзуруме, мавзолеи возводили из каменных блоков. Однако не все они, «разбросанные» по территории, принадлежавшей когда-то империи Сельджуков Рума, а позже анатолийским сельджукам 
и их атабекам, обладают едиными чертами стилистической связи или преемственности, как это могло бы показаться судя по их территориальной близости и общему назначению [1, с.80,81].

Определимся с теми чертами или деталями, которые характеризуют «башенность» мавзолеев, а это прежде всего доминирующий в пространственной композиции строй вертикальных членений. Вертикализм достигался за счет соотношений основных частей сооружения - цоколя, корпуса и покрытия; пропорциями общего объема; абрисом наружного пирамидального или конического «шатра»; подчеркнутой удлиненностью пропорций порталов, входных проемов, ниш, направленностью рисунков архитектурного декора и отделки. Также характерно двухъярусное расположение помещений во внутреннем пространстве, где нижнее служило склепом. Развитый цоколь облицовывался крупными каменными блоками. Покрытие обычно было двойным и внутренний купол, как правило, стрельчатого или эллиптического очертания был защищен коническим или пирамидальным шатром. В некоторых тюрбе сохранились двустронние распашные лестницы, которые ведут к одному из входов верхнего помещения, трактованному в виде богато декорированного портала. В XII в. тип башенного тюрбе получил четкое художественное выражение и стал монументальным сооружением, прославлявшим и увековечивавшим память феодалов, правителей или религиозных деятелей, погребенных в них. Среди башенных мавзолеев на территории Азербайджана, в данном исследовании - на территории Нахчывана, в аспекте сравнительного анализа, рассмотрим тюрбе Юсуфа ибн Кусейра, который был возведен в 1162 г. азербайджанским зодчим Аджеми ибн Абубекр Нахчивани. Этот тип башенного мавзолея из обожженного кирпича и имеющий восьмигранный план, завершен пирамидальным шатром. Архитектурная обработка фасадов создает иллюзию каркасной системы за счет кладки вертикальных угловых лопаток, связанных по верху горизонтальной лентой такой же ширины, и которая обрамляет слегка утопленные прямоугольные плоскости, покрытые орнаментальными плетениями. Переход внешних плоскостей корпуса к шатровому покрытию осуществлен несложным ступенчатым карнизом. Верхняя часть западной грани тюрбе заполнена геометрическим узором, или «гирих», под которым расположена китабе с информацией об имени погребенного и времени постройки мавзолея. Нижняя часть, кроме китабе с крупным «гирих»и «джели куфи», имеет проем со стрельчатой аркой, опирающуюся на трехчетвертные колонки с кубическими капителями. Вход пластически подчеркнут глубоким тимпаном. Надпись, содержащая имя Аджеми ибн Абубекр, профессиональное звание - «ал-бенна», что означает «зодчий-строитель», и нисбу - Нахчыван, вписана вверху орнаментального заполнения первой грани, слева от входа [1, с.86,87]. В Нахчыване примером многогранного башенного мавзолея также является тюрбе Момине Хатун, которое было возведено в 1186 г., и представляющего десятигранный объем, чья высота в 25 м определяет его доминанту в решении пространственной композиции данного месторасположения. Основанием тюрбе служит постамент, облицованный большими глыбами красного диорита. Тюрбе Момине Хатун, являясь произведением Аджеми Абу 
Бекра, в основном повторяет схему мавзолея Юсуфа ибн Кусейра, но в более разработаном варианте. Тут также присутствует иллюзия каркасной системы, только грани и объединяющие их полосы декорированы намного богаче. Плоскости стен между карскасом декорированы тоже более искусно, чем стены тюрбе Кусейра. Заглубленные плоскости стен завершены четко очерченными ступенчтыми арками, светотень мукарнасов которых подчеркивает пластическую выразительность этого архитекурного объема. Переход к наружному покрытию осуществлен сталактитовым карнизом. Купол скорее всего имел вид десятигранной пирамиды. Верхняя часть трактована подобно остальным, а в нижней ее части расположен небольшой прямоугольный проем ведущий в верхнюю камеру, что встречается у всех перечисленных тюрбе, относящихся к XII в. Вход обрамлен неглубокой стрельчатой нишей и китабе с куфической надписью, сообщающей дату строительства, имя и профессиональное звание архитектора - Аджеми ибн Абубекр [1,c.87].

На территории Восточной Анатолии, в провинции Эрзинджан, в городе Кемах, имеются мемориальные памятники, имеющие общие характерные черты с вышеупомянутыми тюрбе в Нахчыване. Это башенное тюрбе Султана Мелик Гази, где общее понимание масс, соотношений, использование кирпича, техника нанесения, глухота поверхностей, включение арки в прямоугольную раму портала и отделочные особенности, показывают важные параллели прежде всего с тюрбе Юсуфа ибн Кусейра. Оно возведено в 1191 г. архитектором Омаром ибн Ибрагим аль-Табари, о чем свидетельствует китабе в верхней части бокового фасада, и представляет собой кирпичный восьмигранный объем с шатровым пирамидальным куполом, чей фасад, так же как и у тюрбе Юсуфа ибн Кусейра, отделан кладкой вертикальных угловых лопаток и по верху объединен горизонтальной полосой. Порталы похожи по композиционным очертаниям, но разнятся в последовательности расположения деталей. Цоколь тюрбе Султан Мелик Гази выше и к порталу следует подняться по лестнице. Хотя фронтон и тимпан анатолийского тюрбе украшены геометрическими мотивами, все остальные детали сооружения, включая слегка утопленные прямоугольные плоскости, являют собой простую кирпичную кладку, в отличие от орнаментов, покрывающих плоскости граней тюрбе Юсуфа ибн Кусейра. На китабе отмечена нисба архитектора - «аль-Табари», т.е. зодчий был из Табари или Табаристана, средневековой провинции XI - XII вв. (с XIII в. - Мазандаран), расположенной на южном побережье Каспийского моря (ныне территория Ирана). Нисба на китабе, указывающая на происхождение архитектора, проводит историко-географические параллели, а значительные сходства и архитектурные приемы, использовавшиеся в соседних государствах, говорят о единых композиционно-художественных и конструктивных тенденциях, о влиянии Нахчывано-Марагинской архитектурной школы на развивающуюся архитектуру Сельджукского Рума, а позже Бейликов (княжеств).

Опираясь на высказанные многими исследователями архитектуры суждения о том, что на территориях сельджукского влияния не было и не могло быть абсолютно единого стиля [3], рассмотрим следующий тип башенного тюрбе, ко- 
торый своей особой стилистикой это подтверждает, а именно - мавзолей Гюлистан, расположенный в селении Гюлистан, на берегу реки Аракс, близ города Джульфа в Нахчыване. Ориентировочно памятник датируется концом XII в. началом XIII в. Тюрбе представляет собой двенадцатигранную башню, стоящую на мощном постаменте. В плане башня посажена на квадратный цоколь и с помощью клинообразно срезанных в двух плоскостях углов цоколя, переходит во втором ярусе в двенадцатигранник. Вертикальный объем сооружен из красного песчаника. Сильно развитый карниз завершает постамент. Под карнизом проходит лента хорошо прорисованного меандра. Над карнизом высится основной объём тюрбе. Пирамидальный шатёр, который должет был венчать сооружение, не сохранился. Поверхность башни тюрбе прорезана ритмически чередующимися стрельчатыми арочками, отличающимися друг от друга заглубленностью и узором декора. Плавность перехода карниза к верхнему объему мавзолея создают вертикально развернутые пальметты, расположенные на выносной плите [2, с. 36-37.]. В архитектуре этого тюрбе присутствуют такие приемы и детали, как композиционное построение орнаменталистики, интересное решение цокольного объема, инкрустирование каменной или кирпичной кладки путем вкрапления каменных деталей другого цвета или включения поливы и т.д., которые получили широкое распространение и в памятниках архитектуры многих городов Восточной Анатолии. Памятники сельджукского султаната, в которые входят и каравансараи, и медресе, и другие примечательные здания крупных городов, таких как Малатья, Эрзурум, мавзолеи в Ахлате, доказывают прямое участие мастеров из Азербайджана в становлении и развитии сельджукской архитектуры [3].

Целый ряд башенных мавзолеев - кюмбетов (так называют только сельджукские мавзолеи) Ахлата и Эрзурума, возведенных в разные периоды сельджукской эпохи, представляет собой источник для исследования данного типа сооружения и проведения параллелей с их нахчыванскими аналогами. Продолжая тему многогранных мавзолеев башенного типа обратимся к аналогичным тюрбе в Восточной Анатолии. Прежде всего большим количеством общих черт с мавзолеем Гюлистан обладают тюрбе Халиме Хатун в Геваше, в иле Ван, построенное в 1325 г., тюрбе Эрзен Хатун, возведенное в 1397 г. и Кешиш Кюмбет, возведенный в XIII - XIV вв. - оба в Ахлате. Под общими чертами прежде всего подразумевается вертикализм, подчеркнутый «башенностью» всех мавзолеев и обязательный цоколь, квадратный в плане, но с клинообразно срезанными в двух плоскостях углами, что помогает ему плавно перейти к многогранной башне тюрбе. Правда, в отличие от тюрбе Гюлистан, ко входу можно подняться по двойной распашной лестнице, расположенной на фасадной части обеих тюрбе. Также как и плоскости граней нахчыванского тюрбе, грани всех трех анатолийских мавзолеев организованы аркатурой и если у Кешиш Кюмбета они только прорисованы, то в тюрбе Халиме Хатун и Эрзен Хатун они богато украшены каменным декором и по центральной оси каждой грани имеются узкие ниши, обрамленные по периметру лентой с разного типа орнаментикой, чаще геометрической, но иногда разнообразными плетенками и «сельджукской цепью». Надвершие арок венчает круг с изображением какого-либо символа, 
например солнечного диска или пяти-, шестиконечной звезды [5]. Фризы под коническим куполом состоят из нескольких полос, каждая полоса несет свой орнамент. Например, первая, сложенная из блоков красного песчаника после подкупольных сталактитов, может быть организована плетенкой, следующая, из каменных блоков светлого оттенка может иметь каллиграфическую надпись сделанную геометрическим «куфи» или более плавным «сульсом». Третья, служащая обрамлением, объединяющим по горизонтали все грани тюрбе, состоит из геометрических форм, чья метрическая компзиция и создает орнамент «гирих». Все это представлено в декоративно-композиционном решении тюрбе Эрзен Хатун в Ахлате и Халиме Хатун в Геваше.

Следующим типом башенных мавзолеев следует считать сооружения с круглыми в плане и цилиндрическими в объеме формами. Такого типа тюрбе также находятся в Ахлате, Эрзуруме и Кемах. Видное место среди цилиндрических тюрбе в Ахлате, возведенных в эпоху сельджуков, то есть с XIII по XIV вв., занимают такие памятники, как парные тюрбе Хусейна Тимура Эсен Текина (1279 г.) и Бугатай Акширин Хатун (1280г.), тюрбе Уста Шакирта (1273 г.), тюрбе Хасана Падишаха (1274 г.), в Эрзуруме - два тюрбе из так называемой группы «Три кюмбета», входящей в архитектурный комплекс Чифте Минарели Медресе и тюрбе Тугай Хатун (XIII в.) в Кемахе. Возведенные практически в одно время, с промежутком в пять-семь лет, все вышеуказанные мавзолеи обобщаются наличием цилиндрической башни, коническим шатром и одинаково решенным объемом цоколя. Среди общих черт также можно выделить: кладку из блоков тесаного камня; портал с сельджукскими элементами, т.е. с прорезанной во фронтоне нишей со сталактитами; декоративное насыщение фасада. Здесь присутствуют арочки, узкие входные проемы, обрамленные вытянутыми нишами со сталактитами и орнаметированными лентами, т.е. с деталями, которые подчеркивают и добавляют вертикальность сооружению. Идентичными по пластичному решению декора являются мавзолеи Хасана Падишаха и Уста Шакирта, где каждая грань обрамлена сдвоенной циркульной аркой, декоративным углом спускающейся на ось симметрии, по которой также располагается узкая аркообразная ниша, обрамленная орнаментальной лентой. Несколько диссонируют своими искаженными пропорциями два кюмбета из эрзерумского комплекса. Из-за их конических шатров, «нахлобученных» и нависающих над объемом башень, сооружения кажутся приземистыми, а не устремленными ввысь, как кюмбеты в Ахлате. Но и здесь плоскость башни покрыта стрельчатыми арками, чья толщина и сдвоенность, а также несущие маленькие колонки с капителями, подпирающими арки, напоминают романский стиль.

В Кемахе расположен мавзолей Тугай Хатун, который в своем объемном и композиционном решении содержит черты сразу нескольких типов мавзолеев. Цилиндрическая башня и гладкая каменная кладка из хорошо пригнанных блоков, а также высокий цоколь с лестницей и конический купол напоминают мавзолеи Ахлата, но портал прямоугольной формы выделенный массивным обрамлением и крупным китабе над входом соотносится с порталами мавзолеев Сул- 
тан Мелика Гази в Кемахе и Юсуфа ибн Кусейра в Нахчыване. Портал богато декорирован руми, вплетенным в «сельджукскую цепь» и изогнутыми ветвями орнамента «ислими».

Особым архитектурным решением выделяется мавзолей Эмира Салтука, входящего в эрзурумскую группу «Три кюмбета». Сооружение датируется XIV в. и представляет собой восьмигранное сооружение соединенного с высоким барабаном и коническим сплюснутым куполом. Многоцветная каменная кладка, называемая «аблаг», барабан под куполом, треугольные фронтоны, круглые арочные ниши ассоциируются с византийскими архитектурными памятниками. В нишах, расположенных по всему радиусу барабана, размещены скульптурные изображения голов животных - быка, орла, летучей мыши, переплетенных змей и даже изображение головы человека между рогами быка. Подобные декоры не характерны для мавзолеев ни в Восточной Анатолии, ни в Нахчыване.

К башенным мавзолеям также принадлежат еще два, стоящих особняком, тюрбе. Это великолепное в своем объемном решении ансамбля тюрбе Мама Хатун (приблизительно между 1192-1202 гг.) в Терджане и тюрбе Шейха Неджмеддина (1222 г.) в Ахлате. Архитектурный ансамбль тюрбе Мама Хатун представляет собой сегментированный объем мавзолея башенного типа с окружающей его стеной. Мавзолей покрыт коническим шатром, как и многие вышеописанные мавзолеи Ахлата и других городов, но его цилиндрическая форма состоит из восьми четвертей других цилиндров, соединенных между собой фризовым обрамлением от которого вертикально по стыкам цилиндриков спускаются нервюры. Фриз абсолютно точно повторяет выпуклости этой «гофрированной» формы мавзолея, а конический купол, покрывая надвершие мавзолея, каждым своим ребром повторяет изгиб цилиндров. Мавзолей Мама Хатун стоит на высоком цоколе, к нему подведена лестница, вход подчеркнут свисающей сверху четвертушкой цилиндра. Стена, окружающая мемориал, диаметром 13,15 м и толщиной 2,45 м, имеет выдающийся в своем декоративном исполнении портал и одинадцать ниш-альковов, размещенных по периметру внутренней части стены, десять из которых с надгробиями. Ниши имеют крестовый свод и циркульную арку. С правой стороны на стену высотой 4,5 м поднимается лестница из семнадцати ступеней $[6$, c.78]. Мавзолеи с гофрированной поверхностью, датируются не раньше XIII в. и зафиксированы как единичные, не связанные с определенной территорией или традицией. Такого типа мавзолеи встречаются еще в Иране (в Радкане), в Турции это также мавзолей Джелал аддина Руми в Конье [4]. Одним из образцов «гофрированных» решений мавзолейной архитектуры XIV в. является мавзолей Джехан Годай Хатун, высотой 30 м, относящегося к ансамблю созданному в 1319-1335 гг. в городе Карабаглар (ныне селение), в Нахчыване.

B XIII - XIV вв. архитектура мавзолеев Азербайджана, в отличие от мавзолеев Восточной Анатолии, изменила свое привычное художественное выражение. Эти изменения произошли в связи с применением нового материала - поливного кирпича и многоцветной наборной мозаики, что дало возможность технике монохромных облицовочных блоков уступить место облицовочной «рубашке» из кирпича различной фактуры и цвета. А «рубашка» определила еще 
две особенности художественого облика мавзолеев XIV в. - парадную многоцветность и двоякое назначение шрифтового орнамента надписей, служивших одновременно средством декора и религиозной пропаганды. В мусульманской архитектуре техника такой «рубашки» носит название «баннаи» и имеет свою историю развития, начиная с VIII века [7, с.10]. Если в XII -XIII вв. надписи на монохромных мавзолеях размещались на фризах, порталах, обрамлениях граней, то в XIV в. многократно повторяющиеся религиозные изречения полностью покрывают плоскости фасадов. Также изменилась трактовка малоприметных входов, уступив место объемно выделенным и декоративно подчернкнутым порталам [1, с.128]. Мавзолей Годай Хатун, круглый в плане, стоит на облицованном крупными каменными плитами цоколе, чей абрис усложнен двенадцатью сомкнутыми полуцилиндрами. Над фризом проходил сталактитовый карниз. Наружное коническое покрытие и внутренний купол не сохранились. Эффектно выделены четыре портала верхней камеры. Композиционые схемы южного, западного и восточного порталов тождественны. Центрами их являются стрельчатые арки со сталактитовым заполнением. В композицию порталов включены китабе с надписями «несхом» и стилизованным «куфи». Северный портал отличается своей заглубленностью в толщу стены. Вся поверхность башни тюрбе декорирована полихромным ковром узорчатой облицовки и модульная сетка, образованная из поставленных по диагонали больших квадратов, заполнена шрифтовым орнаментом повторяющейся надписи «Аллах».

Некоторые особенности объемного решения выделили еще одну группу, получившую название «кубических» мавзолеев, преимущественно расположившиеся на территории Южного Азербайджана, как, например, мавзолей Гонбад-е Сурх в Мараге и составляющий пример Нахчывано-Марагинской архитектурной школы. В Восточной Анатолии кубическим можно назвать мавзолей Шейха Неджмеддина. Единственное среди цилиндрических и полигональных, оно стоит особняком и скромно представляет свою группу. В отличие от многогранных и конических куполов предыдущих мавзолеев, этот имеет пирамидальное покрытие. Над входным проемом находится надпись одного из двух вакуфов, другой написан на куполе здания. Вход организован стрельчатой аркой и нишей со сталактитами, на фасаде находятся оконные проемы.

К портально-купольному типу мавзолеев относится один из двух мавзолеев ханеги Шейх Хорасан на р. Алинджа в Нахчыване, датируемый XIII в. Нижняя часть сооружения имеет форму куба, верхняя - восьмигранника. Переход от куба к восьмиграннику осуществляется с помощью скошенных углов. Верхняя, восьмигранная часть мавзолея состоит из двух частей: нижней - несколько большего размера и верхней - значительно меньшей, сдвинутой под некоторым углом к нижней. Дверной проем, решенный в виде прямоугольной рамы, состоит из богатого орнаментированного обрамления. Китабе над входом с вырезанной по гипсу трехстрочной надписью сообщает дату создания мавзолея. В плане мавзолей почти правильный квадрат со стороной, равной в среднем 5,50 м. Портал организован рельефными панно с прекрасной резьбой по стуку [2, с.75].

Еще один тип мавзолея соотносится с кюмбетом Эмира Али (1306 г.) и анонимным тюрбе в Ахлате, которые отличаются от предыдущих своей необычным 
композиционным решением. Можно сказать, что весь объем здания, состоящий из нескольких других, меньших объемов, был создан с использованием модуля в форме треугольника, если говорить о плоскостном видении (а фасад мавзолея идентифицируется с равнобедренным треугольником), и в форме пирамиды и двускатной крыши, если перевести треугольники в объемы. Основная часть этих мавзолеев напоминает и кочевниковскую палатку, если подразумевать морфологический характер здания, и цоколь, подобно которому обладают мавзолеи Гюлистан в Нахчыване и несколько мавзолеев в Ахлате, такие как: Хасан Падишах, Кешиш, Эрзен Хатун и др. То есть квадратный в плане, со срезанными углами цоколь, в данном случае представляет собой главную часть мавзолея. Кроме того, в отличие от типичных сельджукских порталов с прорезанной стрельчатой аркой и сталактитами на фронтоне, входной проем кюмбета Эмира Али выражен широкой стрельчатой аркой с глубоким айваном, украшенной зубчатым орнаментом над архивольтом и располагается ниже уровня земли. Над восьмигранным барабаном возвышается восьмигранный конус, а перед аркой невысокий парапет с четырьмя башенками разной высоты примыкающие к фасаду. На фасаде с двух сторон находятся филенки с геометрическим орнаментом.

Сельджукский мавзолей, как мемориальное сооружение, был развитым и многообразным по своим композиционным составляющим в формообразовании и использовании строительных и декоративно-отделочных приемов намного больше, чем здания других типологий и функциональных значений, что сделало его особой архитектурной формой в сельджукскую эпоху.

\section{Список используемых источников:}

1. Усейнов М.А., Бретаницкий Л., Саламзаде А.В. История архитектуры Азербайджана. М., 1963. 396 с.

2. Мамед-заде К. М. Строительное искусство Азербайджана (с древнейших времён до ХІХ века). Баку:

Элм, 1983. $335 \mathrm{c.}$.

3. И.А.Орбели. Проблема сельджукского искусства. Доклад на Международном конгрессе по иранскому искусству и археологии. М., 1939.

4.Tипология Среденеазиатских мавзолеев XI-XV в8. Architect. 2011. Apхитектура \& draft. URL: http://www.architekture.info/archi-375

5. İdil Türeli. Türk sanatında altı köşeli yıldız. Yüksek Lisans Tezi, Marmara Üniv.Türkiyat Araştırmaları

Enstitüsü, 2006.

6.Yetkin S.K. Mama Hatun türbesi. Birlington Magazine. 1957.

7. Heeny G. Brickworks. Philadelphia:University of Pennsylvania Press, 2003. P. 208.

(C) 2016, Эды H.A.

Формирование и развитие композиционных и структурных особенностей мавзолеев на территории Восточной Анатолии и Нахчывана с учетом их историко-географических взаимосвязей
(C) 2016, Edi N.A.

Formation and development of compositional and structural features of the mausoleums in Eastern Anatolia and Nakhchivan with regard to their historical and geographical relationships 